\title{
Association between skirt size and chronic liver disease in post-menopausal women: a prospective cohort study within the United Kingdom Trial of Ovarian Cancer Screening (UKCTOCS)
}

P. M. Trembling ${ }^{1 *}$, S. Apostolidou², A. Gentry-Maharaj², J. Parkes ${ }^{3}$, A. Ryan², S. Tanwar ${ }^{1}$, M. Burnell², U. Menon ${ }^{2+}$ and W. M. Rosenberg ${ }^{1+}$

\begin{abstract}
Background: We investigated the association between self-reported skirt size (SS) and change in SS, and incidence of chronic liver disease (CLD) in a prospective cohort study of women recruited to the UKCTOCS trial.

Methods: Women recruited to UKCTOCS in England without documented CLD self-reported their current UK SS during trial participation and were asked to recall their SS when aged in 20s (via completion of a questionnaire 3-5 years after recruitment). Participants were followed up via electronic health record linkage and hazard ratios (HR) calculated for incident liver-related events (LRE).

Results: Three hundred twenty-two (0.3\%) of 94,124 women experienced a first LRE. Compared to SS $\leq 16$, rates of LRE were higher in the SS $\geq 18$ groups (both when aged in 20s and at questionnaire completion). Event rates were higher if there was no change in SS or an increase in SS, compared to a decrease in SS.

In the models adjusted for potential confounders, HRs for LRE were higher in the groups of women reporting SS $\geq 18$ both when aged in $20 \mathrm{~s}(\mathrm{HR}=1.39(95 \% \mathrm{Cl} ; 0.87-2.23))$ and at questionnaire completion ( $\mathrm{HR}=1.37(95 \%$ $\mathrm{Cl} ; 1.07-1.75))$. Compared to a decrease in SS, HRs were higher in the no change $(\mathrm{HR}=1.78(95 \% \mathrm{Cl} ; 0.95-3.34))$ and increase $(\mathrm{HR}=1.80(95 \% \mathrm{Cl} ; 1.01-3.21))$ groups.
\end{abstract}

Conclusion: CLD is associated with high SS and an increase in SS over time. These data suggest SS can be used in simple public health messages about communicating the risk of liver disease.

Trial Registration: UKCTOCS is registered as an International Standard Randomised Controlled Trial, number ISRCTN22488978. Registered 06/04/2000.

Keywords: Chronic liver disease, Cirrhosis, Skirt size, Body mass index, Obesity, UKCTOCS

\footnotetext{
*Correspondence: p.trembling@ucl.ac.uk

${ }^{\dagger}$ Equal contributors

${ }^{1}$ Institute for Liver and Digestive Health, Division of Medicine, University

College London, Royal Free Hospital, Rowland Hill Street, NW3 2PF, London,

UK

Full list of author information is available at the end of the article
} 


\section{Background}

Chronic liver disease (CLD) is a leading cause of death in the UK. It is estimated that 60,000 people in the UK have cirrhosis $[1,2]$ but over half of those affected are unaware of the diagnosis [3]. The main causes of CLD are alcohol, non-alcoholic fatty liver disease (NAFLD) and viral hepatitis.

NAFLD describes the process of hepatic accumulation of fat, ranging from benign steatosis, via liver inflammation (steatohepatitis) to progressive liver fibrosis and eventually cirrhosis, and can be considered the pathological manifestation in the liver of the metabolic syndrome. In addition to type 2 diabetes, hypertension and hypercholesterolaemia, high body mass index (BMI) is a significant driver for NAFLD, and is associated with increased risk of heart disease and stroke [4]. Although BMI is commonly used as a measure of body fat, it has been demonstrated that waist and hip measurements may be stronger predictors of body fat than BMI $[5,6]$.

We have previously demonstrated the association between increasing BMI and risk of CLD. In a large cohort of post-menopausal women we observed more clinical events attributable to cirrhosis amongst women who were overweight or obese compared to those with a normal BMI. Although there was no evidence of significant interaction between alcohol and BMI, the highest risk of liver disease was seen in women who were overweight or obese and consumed the most alcohol [7].

Skirt size (SS) could be an easily understood surrogate for BMI to communicate public health messages about the risks of obesity. Increase in self-reported SS in participants in the United Kingdom Collaborative Trial of Ovarian Cancer Screening (UKCTOCS) has been shown to be associated with increased breast cancer risk. A unit increase in UK SS (e.g. 12 to 14 ) every 10 years between 25 and postmenopausal age is associated with postmenopausal breast cancer risk of $33 \%$. Validation of these results could provide women with a simple and easy to understand message, using SS [8]. We now explore the association between SS and change in SS and the incidence of CLD.

\section{Methods}

\section{Study population}

This prospective cohort study was nested in UKCTOCS, a UK-based randomised controlled trial investigating the effect of ovarian cancer screening on mortality. The trial design is described elsewhere [7-11]; briefly, between April 2001 and October 2005, post-menopausal women aged 50-74 in England, Wales and Northern Ireland were invited at random and 202,638 participants recruited to the trial. Participants were randomly allocated to one of three arms (no screening, annual serum CA125 measurement and then transvaginal ultrasound as a second line test, or ultrasound only). Recent data from the trial have demonstrated the predictive value of changes in CA125 levels to predict ovarian cancer [12], and reduced mortality in the multimodal arm [13].

UKCTOCS was approved by the UK North West Multicentre Research Ethics Committee (North West MREC 00/8/34). All women provided written consent. The current study was approved by the National Research Ethics Service (NRES) Committee London - Bentham (Ref: 05/Q0505/57) on 10th August 2011.

\section{Exposures}

The exposures of interest in this study were BMI and SS of participants. At the time of recruitment, participants completed a questionnaire, which included self-reported height and weight. BMI was calculated (BMI $\left(\mathrm{kg} / \mathrm{m}^{2}\right)=$ weight $(\mathrm{kg}) /$ height $\left.(\mathrm{m})^{2}\right)$ and categorised according to the World Health Organization's definitions; normal $(<25 \mathrm{~kg} /$ $\left.\mathrm{m}^{2}\right)$, overweight $\left(25-<30 \mathrm{~kg} / \mathrm{m}^{2}\right)$ or obese $\left(\geq 30 \mathrm{~kg} / \mathrm{m}^{2}\right)$. There were some extreme values in self-reported data and as there are no existing population estimates for the range of BMI we applied a pragmatic approach in order to include participants with biologically plausible BMI values. Therefore, participants were excluded if their reported height lay outside the range $140-210 \mathrm{~cm}$, or their weight lay outside the range $25-200 \mathrm{~kg}$, or where the calculated BMI was outside the range $16-65 \mathrm{~kg} / \mathrm{m}^{2}$.

Participants were asked to complete a follow-up questionnaire 3-5 years post randomisation, and were asked to estimate their UK SS when they were in their early twenties and to report their current SS. Using the two SS responses overall change in SS and change in SS per year were calculated. In the UK SS range comprises of even numbers, for example in increase in SS from 12 to 14 is an increase in one UK SS.

\section{Categorisation of exposure variables}

BMI was categorised according to World Health Organization classification as normal, overweight, or obese. SS was categorised using UK dress sizes as $\leq 16$ and $\geq 18$; the latter cut-off selected because of its association with an increased risk of cardiovascular morbidity [14]. The British Standards Institution defines UK size 16 as $100-104 \mathrm{~cm}$, and size 18 as $105-109 \mathrm{~cm}$, measured at the hips [15]. Change in SS was categorised as decrease, no change or increase in SS between when participants were in their early 20 s and at their current age.

\section{Covariates}

Participants reported, via the follow-up questionnaire, known comorbidities, comprising hypertension, heart disease, hypercholesterolaemia, stroke, diabetes, rheumatoid arthritis, osteoarthritis, osteoporosis ("do you have/are you being treated for any of the following conditions?"), and whether they currently smoked, all categorised as yes/no. 
Participants were asked "approximately how much alcohol on average do you drink each week, assuming one drink = a glass of wine, half a pint of lager or cider, a measure of spirits?" This was then categorised as none, $<1-15$ units/ week, 16-20 units/week and $\geq 21$ units/week, assuming one drink is equivalent to one UK unit $(10 \mathrm{ml}$ or $8 \mathrm{~g}$ of pure alcohol) [16].

Participants were assigned a deprivation score using the Index of Multiple Deprivation 2007 (IMD) (continuous variable) [17], with a higher score indicating higher deprivation.

\section{Follow up}

Participants in this study were followed through a 'flagging' study with NHS Digital which provided data on cancer registrations and deaths, with diagnosis and/or cause of death coded according to the International Classification of Diseases, version 10 (ICD-10). Hospital inpatient and outpatient data for 2001-10 were also available through linkage to the Hospital Episodes Statistics (HES) database. Each inpatient HES episode record reports a main diagnosis and up to 19 additional diagnoses. Outpatient records report a main diagnosis and up to 11 further diagnoses. Death records report the primary death code and additional diagnoses documented on the death certificate, comprising both ICD-10 codes and free text. Only participants in England were included in this study, due to availability of their relevant HES data. Participants entered the study at the point of return of the follow-up questionnaire, as this was the date that current comorbidities and SS data were ascertained. Women with pre-existing liver disease were excluded if a code of interest had been registered between recruitment to UKCTOCS and return of follow-up questionnaire.

\section{Outcome}

First liver-related event (LRE) was deemed the main outcome measure. LRE was defined as a participant's first presentation of a hospital admission, outpatient appointment or cancer registration with, or death from, a relevant ICD-10 code. These codes were K70 (alcoholic liver disease), K73 (chronic hepatitis) and K74 (fibrosis and cirrhosis) and are consistent with codes employed in other UK studies of cirrhosis $[1,18]$. In addition K76 (other diseases of the liver, including fat) and codes related to decompensated liver disease (I85 (oesophageal varices), Z94.4 (liver transplant) and C22.0 (hepatocellular carcinoma)) were included. Death certificates were interrogated for ICD-10 codes of interest and free text relating to alcoholic liver disease or fatty liver.

\section{Statistical analysis}

For the incidence analyses person-years of follow-up was used as the denominator. Participants contributed person- years until the date of censoring (February 1, 2013), date of first presentation with an LRE or death from any other cause.

Crude incidence was calculated for each BMI group, each SS when aged in 20s group, each SS at questionnaire completion group, and change in SS group.

\section{Survival analysis}

Potential confounding risk factors including self-reported comorbidities were analysed in univariate Cox proportional hazards models to determine their individual risks in liver disease.

Cox proportional hazards models were used to calculate hazard ratios (HRs) of first LRE, with 95\% confidence intervals (CI). For each exposure described above, BMI, SS when aged in 20s and SS at questionnaire completion were analysed as continuous coavariates, and then BMI, SS when aged in 20s, SS at questionnaire completion and overall change in SS as categorical covariates. For each outcome, univariate models were produced. Smoking and deprivation were then added (partially adjusted), and then all covariates listed above were added, with abstinence and alcohol consumption $\geq 21$ units/week as individual indicator variables (fully adjusted).

All analyses were performed using SPSS (version 22, SPSS Inc., Chicago, IL, USA).

\section{Results}

\section{Sample characteristics}

Of the 157,996 UKCTOCS participants resident in England, 62,870 were excluded including 321 women who experienced an LRE or died between recruitment and return of questionnaire and 14,295 (9\%) with no data on smoking. There was some missing SS data, and the resulting effective sample size for this study was 94,124 (Fig. 1).

Overall, 97\% of the participants were Caucasian, 36\% were smokers, $55 \%$ were overweight $(37 \%)$ or obese $(18 \%)$. Median age at completion of the questionnaire was 64 years. Baseline characteristics are shown in Table 1.

\section{Distributions of $\mathrm{BMI}$ and skirt size}

The distributions of BMI, SS when aged in 20s, SS at questionnaire completion and annual change in SS are shown in Fig. 2. Median BMI was $25.57 \mathrm{~kg} / \mathrm{m}^{2}$ (IQR 22.79-28.36), median SS when aged in 20s was 12 (IQR 10-14), median SS at questionnaire completion was 14 (IQR 12-16), and the median change in SS unit per year was 0.0323 (IQR 0.0123-0.0523). This is the equivalent to an increase of one SS unit (e.g. from 12 to 14) every 31 years.

Visual inspection of the histograms (Fig. 2), quantilequantile plots and box plots for each outcome variable showed that each variable was approximately normally 


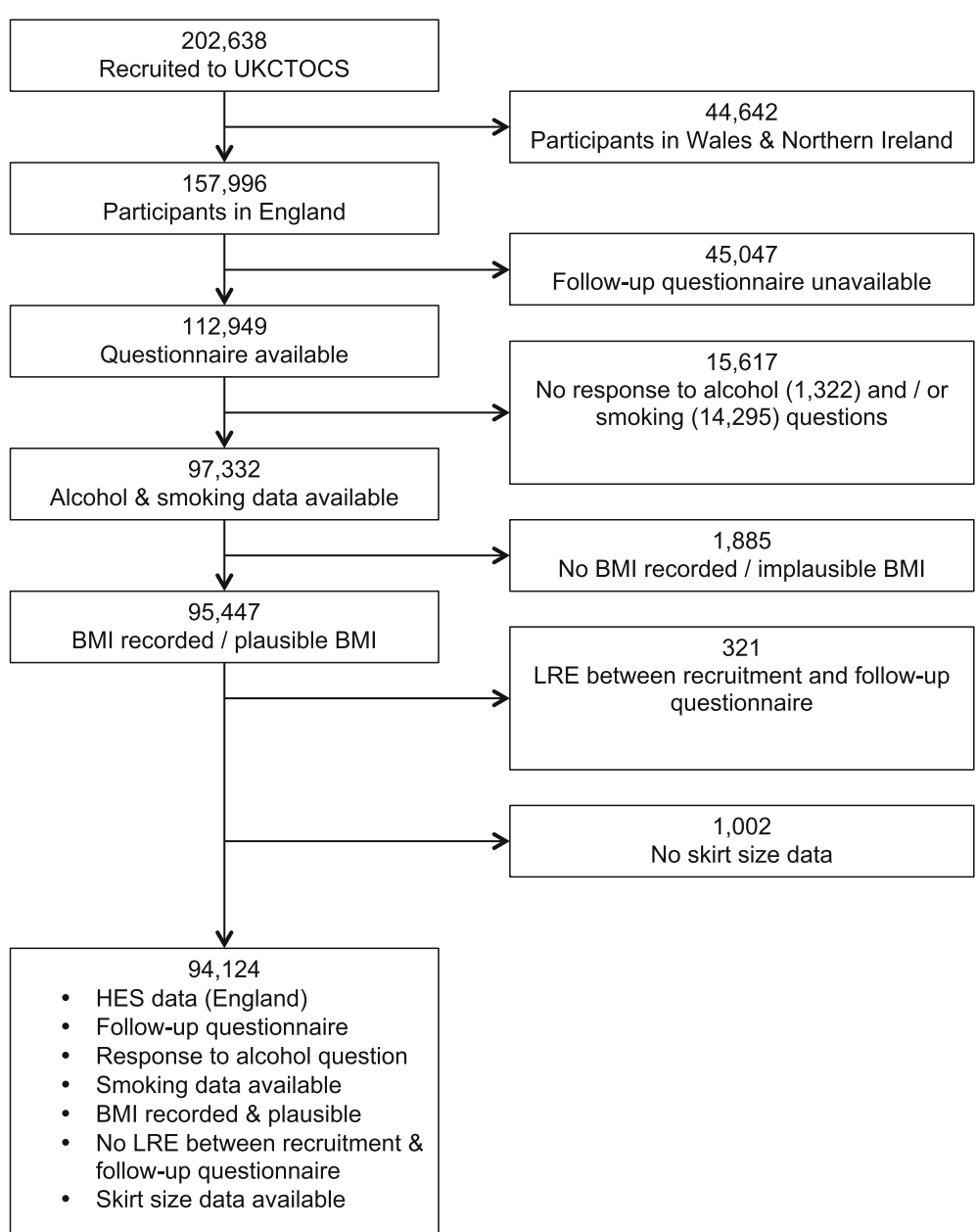

Fig. 1 Composition of the final study cohort and its derivation from the UKCTOCS cohort

distributed, but with right-skewness seen with BMI, SS when aged in 20s and SS at questionnaire completion (BMI - skewness $1.368(\mathrm{SE}=0.008)$, kurtosis 4.033 $(\mathrm{SE}=0.016) ; \mathrm{SS}$ when aged in $20 \mathrm{~s}-$ skewness 1.442 $(\mathrm{SE}=0.008)$, kurtosis 5.787 ( $\mathrm{SE}=0.016)$; $\mathrm{SS}$ at questionnaire completion - skewness $0.999(\mathrm{SE}=0.008)$, kurtosis $2.415(\mathrm{SE}=0.016)$; change in SS per year - skewness 0.470 $(\mathrm{SE}=0.008)$, kurtosis $3.095(\mathrm{SE}=0.016)$.

\section{Crude event rates}

Three hundred and twenty two $(0.34 \%)$ women experienced a first LRE over the follow up period. Crude rates of LRE are shown in Table 2, categorised by BMI, SS when aged in 20s, SS at questionnaire completion and overall change in SS. The most common incident ICD10 code was K76 (Additional file 1: Table S1).

The rate of LRE increased with increasing BMI. Comparison of rates of LREs in SS categories found a higher incidence in participants with $S S \geq 18$, compared to participants with $\mathrm{SS} \leq 16$, both in the SS when aged in 20 s group and the SS at questionnaire completion group. In terms of overall change in SS, event rate was lowest in the group where SS decreased. The rate was higher if there was no change, and highest if there was an increase in SS (Fig. 3).

\section{Survival analysis \\ Cox proportional model estimates for each potential confounder}

There were significant associations between LRE and smoking, deprivation, BMI, heart disease, hypercholesterolaemia, diabetes, rheumatoid arthritis, alcohol abstinence and alcohol excess ( $\geq 21$ units/week) (Additional file 1: Table S2). A "J-shaped" relationship between alcohol and risk of CLD is seen, and we have previously explored this finding in the UKCTOCS population [7].

\section{Cox proportional model estimates for each exposure}

When SS when aged in 20 s $\geq 18$ was compared to $\leq 16$, HR for LRE was increased in the unadjusted $(H R=1.81$ 
Table 1 Baseline characteristics and number of first events according to BMl category, and for all participants

\begin{tabular}{|c|c|c|c|c|}
\hline \multirow[t]{2}{*}{ Characteristic } & \multicolumn{3}{|c|}{ BMl category $\left(\mathrm{kg} / \mathrm{m}^{2}\right)$} & \multirow{2}{*}{$\begin{array}{l}\text { All } \\
\text { participants }\end{array}$} \\
\hline & $<25$ & $25-<30$ & $\geq 18$ & \\
\hline Total, $n$ (\% of all participants) & $42,077(44.7)$ & $34,690(36.9)$ & $17,260(18.3)$ & 94,124 \\
\hline LRE, $n$ (\% of all participants) & $102(31.7)$ & $123(38.2)$ & $97(30.1)$ & 322 \\
\hline Age at questionnaire return, median years (range) & $63(52-80)$ & $64(53-80)$ & $64(53-80)$ & $64(52-80)$ \\
\hline IMD, mean (SD) & $17.0(13.1)$ & $18.7(14.1)$ & $21.3(15.4)$ & $18.4(14.0)$ \\
\hline Smoker, $n(\%)$ & $14,632(34.8)$ & $12,511(36.1)$ & $6548(37.7)$ & $33,691(35.8)$ \\
\hline Hypertension, $n$ (\%) & $9382(22.3)$ & $11,970(34.5)$ & $8307(47.9)$ & $29,659(31.5)$ \\
\hline Heart disease, $n(\%)$ & $1698(4.0)$ & $2052(5.9)$ & $1392(8.0)$ & $5142(5.5)$ \\
\hline Hypercholesterolaemia, n (\%) & $7901(18.8)$ & $9044(26.1)$ & $5369(30.9)$ & $22,314(23.7)$ \\
\hline Stroke, $n(\%)$ & $523(1.2)$ & $552(1.6)$ & $314(1.8)$ & $1389(1.5)$ \\
\hline Diabetes, $n(\%)$ & $827(2.0)$ & $1653(4.8)$ & $2221(12.8)$ & $4701(5.0)$ \\
\hline Rheumatoid arthritis, $n$ (\%) & $1592(3.8)$ & $1742(5.0)$ & $1185(6.8)$ & $4519(4.8)$ \\
\hline Osteoarthritis, n (\%) & $5503(13.1)$ & $5822(16.8)$ & $4016(23.1)$ & $15,341(16.3)$ \\
\hline Osteoporosis, $n$ (\%) & $3808(9.1)$ & $2082(6.0)$ & $770(4.4)$ & $6660(7.1)$ \\
\hline \multicolumn{5}{|l|}{ Alcohol consumption (units/week), $n(\%)$} \\
\hline None & $8365(19.9)$ & $8.043(23.2)$ & $5432(31.3)$ & $21,840(23.2)$ \\
\hline$<1-15$ & $31,567(75.0)$ & $25,095(72.3)$ & $11,347(65.4)$ & $68,009(72.3)$ \\
\hline $16-20$ & $1436(3.4)$ & $1063(3.1)$ & $364(2.1)$ & $2863(3.0)$ \\
\hline$\geq 21$ & $709(1.7)$ & $489(1.4)$ & $214(1.2)$ & $1412(1.5)$ \\
\hline \multicolumn{5}{|l|}{ Skirt size when aged in $20 \mathrm{~s}, n(\%)$} \\
\hline$\leq 16$ & $41,428(98.5)$ & $33,835(97.5)$ & $15,691(90.4)$ & $90,954(96.6)$ \\
\hline$\geq 18$ & $649(1.5)$ & $855(2.5)$ & $1666(9.6)$ & $3170(3.4)$ \\
\hline \multicolumn{5}{|l|}{ Skirt size at time of questionnaire completion, $n(\%)$} \\
\hline$\leq 16$ & $40,792(96.9)$ & $26,982(77.8)$ & $4481(25.8)$ & $72,255(76.8)$ \\
\hline$\geq 18$ & $1285(3.1)$ & $7708(22.2)$ & $12,876(74.2)$ & $21,869(23.2)$ \\
\hline Change in skirt size, median (interquartile range) & $0.0244(0.03)$ & $0.0408(0.04)$ & $0.0667(0.05)$ & $0.0323(0.04)$ \\
\hline \multicolumn{5}{|l|}{ Overall change in skirt size, $n(\%)$} \\
\hline Decrease & $4811(11.4)$ & $1153(3.3)$ & $362(2.1)$ & $6326(6.7)$ \\
\hline No change & $12,344(29.3)$ & $3422(9.9)$ & $731(4.2)$ & $16,497(17.5)$ \\
\hline Increase & $24,922(59.2)$ & $30,115(86.8)$ & $16,264(93.7)$ & $71,301(75.8)$ \\
\hline
\end{tabular}

(95\% CI; 1.14-2.87)), partially adjusted ( $\mathrm{HR}=1.68(95 \% \mathrm{CI}$; $1.06-2.68)$ ) and fully adjusted $(\mathrm{HR}=1.39$ (95\% CI; $0.87-$ 2.23)) models. The confidence interval for the fully adjusted model crossed unity, suggesting that a component of the risk may be partially attributable to one or more of the metabolic comorbidities (hypertension, hypercholesterolaemia, diabetes and heart disease) (Table 3). Comparing the two SS groups at questionnaire completion, HRs were again higher in the higher SS group in all models $(\mathrm{HR}=1.69$ (95\% CI; 1.34-2.13) in the unadjusted model, $\mathrm{HR}=1.58$ (95\% CI; $1.25-2.00)$ in the partially adjusted model, $\mathrm{HR}=$ 1.37 (95\% CI; 1.07-1.75) in the fully adjusted model).

Compared to women whose SS decreased between their 20s and questionnaire completion, HRs were higher in those whose SS did not change and highest in those whose SS increased (Table 3).
Compared to normal BMI, overweight and obesity were significantly associated with LRE in all models (Table 3).

\section{Discussion}

\section{Main findings}

We have demonstrated in a cohort of post-menopausal women that a larger SS is associated with subsequent risk of LRE, and a SS of $\geq 18$ compared to a SS of $\leq 16$ is associated with a higher HR than that associated with overweight, but less than that associated with obesity when compared to a normal BMI. Although the risks of high SS and high BMI may not be directly comparable, the value of communicating public health messages in terms of SS lies in better understanding amongst the general public compared to communicating the risk of liver disease associated with increased BMI. 

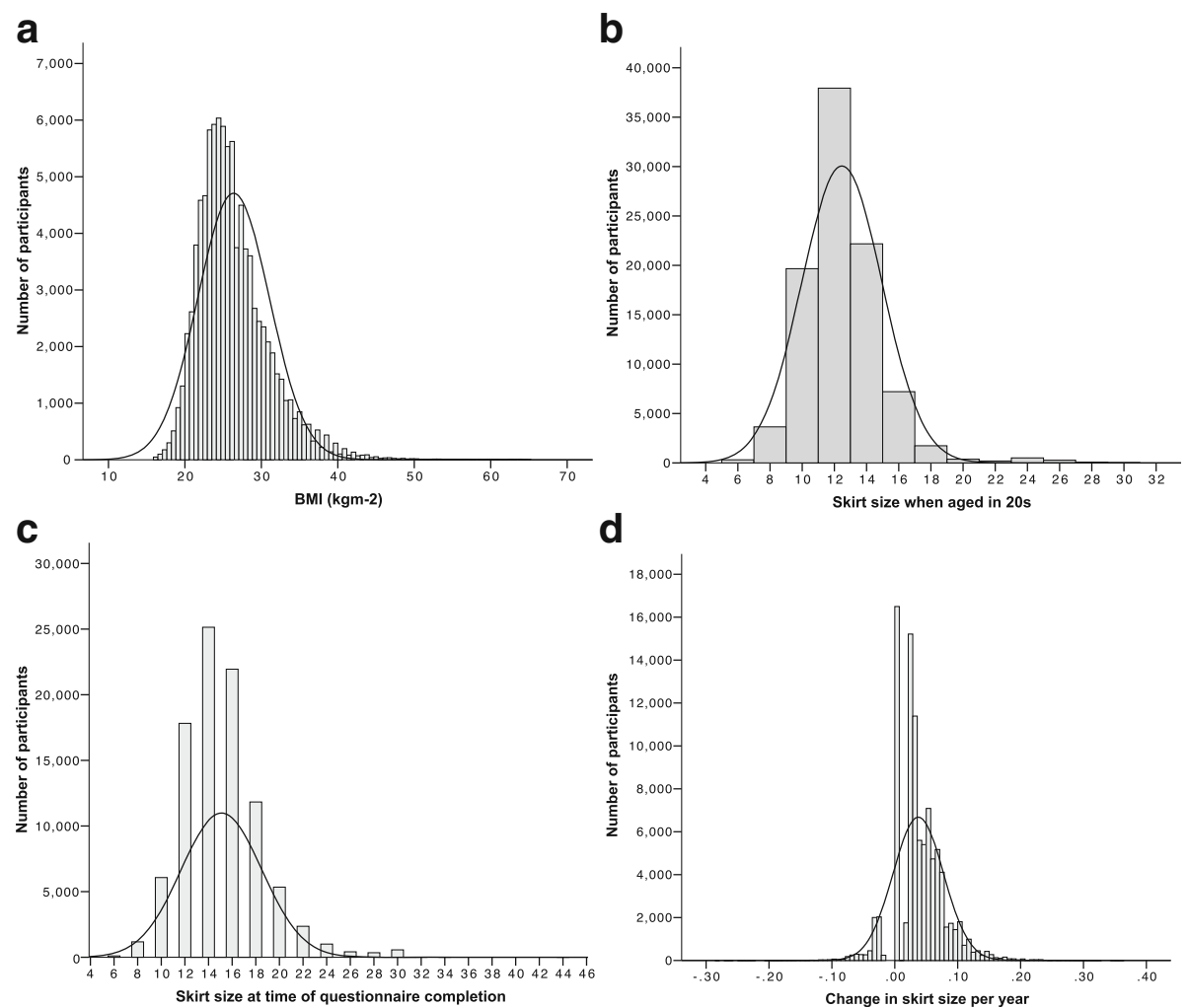

Fig. 2 Distributions of a) BMI, b) skirt size in 20s, c) skirt size at questionnaire completion, and d) change in skirt size per year

In our cohort, $76 \%$ reported an increase in SS between when aged in 20s and questionnaire completion. This is consistent with previous studies reporting the change in body composition associated with transitioning from pre-menopausal to post-menopausal status, with an increase in central adiposity manifested by increased waist circumference (WC) [19].

When BMI and SS (as continuous variables) were combined, the HR for each was reduced, suggesting that SS (and BMI) is an independent predictor for NAFLD,

Table 2 Crude rates of liver-related event. Events per 1000 participant years (95\% confidence intervals)

\begin{tabular}{lll}
\hline Exposure & & Event rate \\
\hline BMI $\left(\mathrm{kg} / \mathrm{m}^{2}\right)$ & $<25$ & $0.453(0.369-0.550)$ \\
& $25-<30$ & $0.661(0.549-0.788)$ \\
& $\geq 30$ & $1.044(0.847-1.273)$ \\
Skirt size in 20s & $\leq 16$ & $0.621(0.553-0.696)$ \\
& $\geq 18$ & $1.124(0.677-1.755)$ \\
Skirt size at questionnaire completion & $\leq 16$ & $0.550(0.479-0.629)$ \\
& $\geq 18$ & $0.928(0.762-1.120)$ \\
Change in skirt size/year & Decrease & $0.3867(0.206-0.661)$ \\
& No change & $0.599(0.449-0.784)$ \\
& Increase & $0.669(0.590-0.757)$ \\
\hline
\end{tabular}

and that SS may reflect centripetal fat distribution associated with NAFLD better than BMI.

NAFLD is poorly identified in primary care and it is conceivable that a proportion of individuals with LREs that were not associated with an ICD-10 code for fatty liver may have had NAFLD. SS may be a better predictor of NAFLD (obesity) related liver disease than a clinical diagnosis of NAFLD in primary care.

Although the codes or text contributing most commonly to LRE were those representing NAFLD, those representing alcoholic liver disease contributed to nearly $10 \%$ of LREs (Additional file 1: Table S1). Regardless of the aetiology of CLD, the clinicopathological pathway is progressive fibrosis leading to cirrhosis [20] and there may be common pathways in which alcohol and BMI damage the liver [21]. Patterns of alcohol consumption in women are changing; 16\% of women in England consume above recommended limits, and this practice is highest in the 55-64 year old group [22], and the rate of alcohol-related hospital admissions by women increased by over 30\% between 2008 and 2015 [23].

\section{Strengths and limitations}

Strengths of this study include the large size of the cohort, the prospective design and the independence of data capture for outcomes. We used ICD-10 codes for cirrhosis 


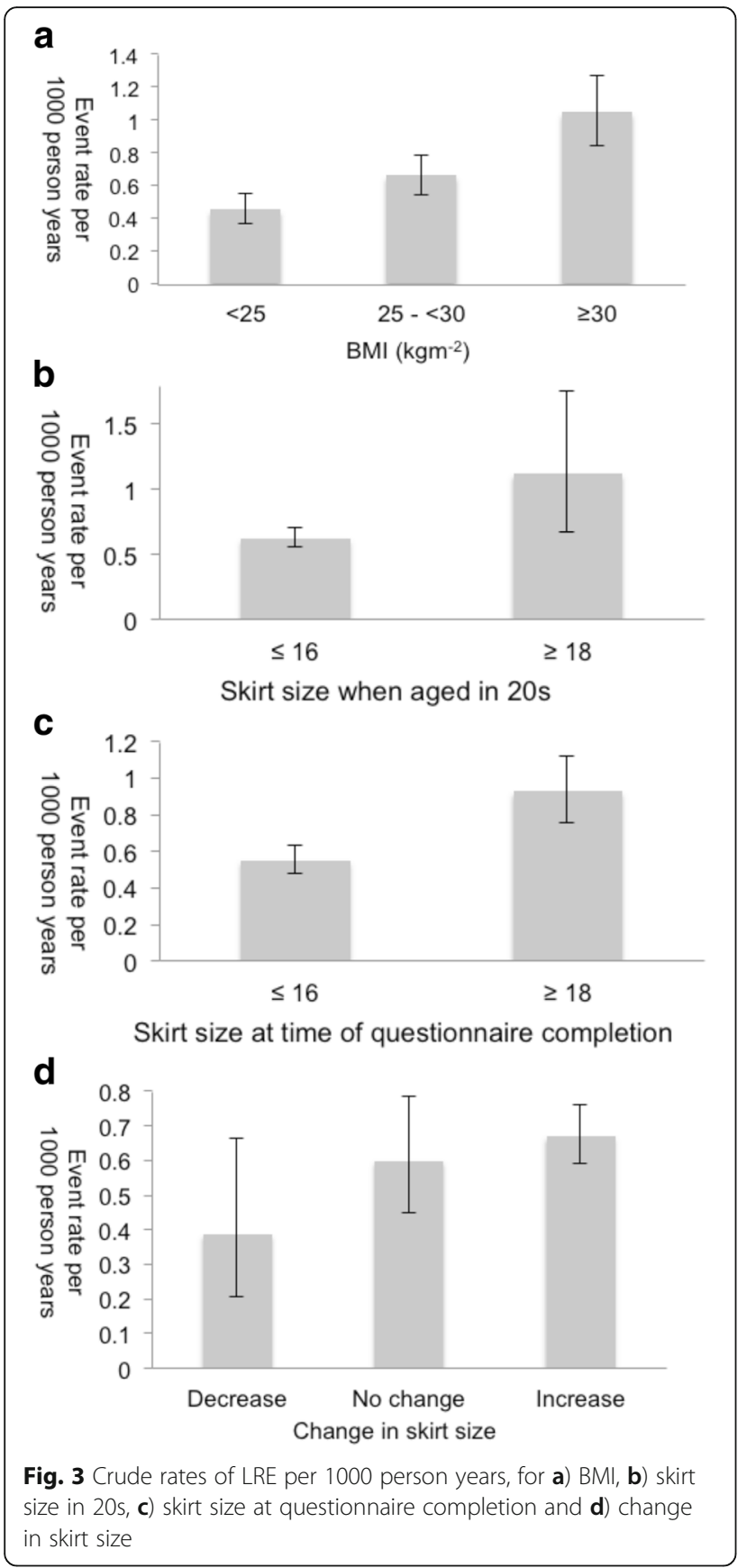

that have been used in other studies, but in an attempt to maximise the ability to identify liver disease we also included codes relating to clinical consequences of advanced cirrhosis, the events defining decompensated liver disease. Evaluation of numerous possible confounders including self reported known comorbidities and socioeconomic status minimised bias.

Limitations include the reliance of self-reporting of SS, height and weight and co-morbidities. There is some evidence supporting the reliability of self-reporting of biometric data including height and weight [24-28], notably in a longitudinal study of older people [29]. There was a 30-50 year recall of participants' SS when aged in their 20s, raising the possibility of recall error. Several studies have demonstrated good accuracy in recalled weight, with some data indicating underestimation in those with higher BMI [30-33]. We postulate that participants may have a better recollection of their skirt size than their weight or waist size. There was a 25 year age range in participants, and older participants may have had children at a younger age than younger participants, which may have increased their SS [34].

It is likely that there will be some variability between SS over the period between the two SS estimates. In the UK there is no requirement for manufacturers to adhere to the standard sizing. In addition the phenomenon of vanity sizing is recognised, where clothes with the same size label have become larger over recent decades. This has become a common practice of clothing manufacturers, which may potentially impede comparisons of sizes over time [35]. Indeed, the Chief Medical Officer for England has highlighted this 'size inflation' as a risk for society normalising overweight [36].

Reliance on ICD-10 to define events may result in errors due to mis-coding. We used three independent sources in an attempt to reduce risk of non-coding. Further, HES data may not capture some areas of healthcare, including the private sector. Finally, although attempts were made to ensure UKCTOCS was representative of the general population, there was a 'healthy volunteer effect' on overall and cause-specific mortality, which may affect the generalisability of our findings [17].

\section{Other studies}

The link between obesity and the risk of NAFLD is strong, with a clear dose-response relationship demonstrated in cross-sectional studies [37], although data from prospective studies are limited [38, 39].

However, few studies have investigated the relationship between SS and disease. Ours is the only study we are aware of that has investigated the association between SS and liver disease. The UKCTOCS group demonstrated an increase in risk of breast cancer with increase in SS over time [12].

A study nested in the Netherlands Cohort Study on Diet and Cancer reported increased risk of endometrial cancer with increasing SS. The correlation between selfreported SS and self-reported WC, self-reported hip circumferences and BMI based on self-reported height and weight in 1334 women, were $0.71,0.78$ and 0.76 respectively [40].

A study of 293 men and women found that professionally measured WC correlated closely with clothing size in both men and women ( $r=0.80$ and 0.78 , respectively) [41]. 
Table 3 Hazard ratios of first events for skirt size in 20s, skirt size at questionnaire completion, BMI and change in skirt size (95\% confidence intervals and $p$ values)

\begin{tabular}{|c|c|c|c|c|}
\hline \multicolumn{4}{|l|}{ Variable } & \multirow{2}{*}{$\begin{array}{l}\text { Hazard ratio }(95 \% \mathrm{Cl}) \\
1.062(1.022-1.104) \\
p=0.002\end{array}$} \\
\hline \multirow[t]{7}{*}{ Skirt size when aged in 20s } & \multirow[t]{3}{*}{ Univariate } & Continuous & & \\
\hline & & Categorical & $\leq 16$ & Reference \\
\hline & & & $\geq 18$ & $\begin{array}{l}1.806(1.136-2.871) \\
p=0.012\end{array}$ \\
\hline & \multirow[t]{2}{*}{ Adjusted for smoking, deprivation } & & $\leq 16$ & Reference \\
\hline & & & $\geq 18$ & $\begin{array}{l}1.681(1.057-2.675) \\
p=0.028\end{array}$ \\
\hline & \multirow{2}{*}{$\begin{array}{l}\text { Adjusted for age, smoking, deprivation, hypertension, } \\
\text { heart disease, hypercholesterolaemia, stroke, diabetes, } \\
\text { rheumatoid arthritis, osteoarthritis, osteoporosis, } \\
\text { alcohol abstinence, alcohol } \geq 21 \text { units/week }\end{array}$} & & $\leq 16$ & Reference \\
\hline & & & $\geq 18$ & $\begin{array}{l}1.390(0.868-2.226) \\
p=0.171\end{array}$ \\
\hline \multirow[t]{7}{*}{$\begin{array}{l}\text { Skirt size at time of questionnaire } \\
\text { completion }\end{array}$} & \multirow[t]{3}{*}{ Univariate } & Continuous & & $\begin{array}{l}1.091(1.062-1.121) \\
p<0.0005\end{array}$ \\
\hline & & Categorical & $\leq 16$ & Reference \\
\hline & & & $\geq 18$ & $\begin{array}{l}1.690(1.342-2.129) \\
p<0.0005\end{array}$ \\
\hline & \multirow[t]{2}{*}{ Adjusted for smoking, deprivation } & & $\leq 16$ & Reference \\
\hline & & & $\geq 18$ & $\begin{array}{l}1.579(1.250-1.995) \\
p<0.0005\end{array}$ \\
\hline & \multirow{2}{*}{$\begin{array}{l}\text { Adjusted for age, smoking, deprivation, hypertension, } \\
\text { heart disease, hypercholesterolaemia, stroke, diabetes, } \\
\text { rheumatoid arthritis, osteoarthritis, osteoporosis, alcohol } \\
\text { abstinence, alcohol } \geq 21 \text { units/week }\end{array}$} & & $\leq 16$ & Reference \\
\hline & & & $\geq 18$ & $\begin{array}{l}1.369(1.071-1.749) \\
p=0.012\end{array}$ \\
\hline \multirow[t]{10}{*}{ BMI $\left(\mathrm{kg} / \mathrm{m}^{2}\right)$} & \multirow[t]{4}{*}{ Univariate } & Continuous & & $\begin{array}{l}1.063(1.044-1.082) \\
p<0.0005\end{array}$ \\
\hline & & Categorical & $<25$ & Reference \\
\hline & & & $\geq 25-<30$ & $\begin{array}{l}1.461(1.123-1.899) \\
p=0.005\end{array}$ \\
\hline & & & $\geq 30$ & $\begin{array}{l}2.308(1.748-3.047) \\
p<0.0005\end{array}$ \\
\hline & \multirow[t]{3}{*}{ Adjusted for smoking, deprivation } & & $<25$ & Reference \\
\hline & & & $\geq 25-<30$ & $\begin{array}{l}1.403(1.076-1.830) \\
p=0.012\end{array}$ \\
\hline & & & $\geq 30$ & $\begin{array}{l}2.162(1.631-2.864) \\
p<0.0005\end{array}$ \\
\hline & \multirow{3}{*}{$\begin{array}{l}\text { Adjusted for age, smoking, deprivation, hypertension, } \\
\text { heart disease, hypercholesterolaemia, stroke, diabetes, } \\
\text { rheumatoid arthritis, osteoarthritis, osteoporosis, } \\
\text { alcohol abstinence, alcohol } \geq 21 \text { units/week }\end{array}$} & & $<25$ & Reference \\
\hline & & & $\geq 25-<30$ & $\begin{array}{l}1.353(1.034-1.770) \\
p=0.028\end{array}$ \\
\hline & & & $\geq 30$ & $\begin{array}{l}1.880(1.395-2.533) \\
p<0.0005\end{array}$ \\
\hline \multirow[t]{5}{*}{ Change in skirt size/year } & \multirow[t]{3}{*}{ Univariate } & Categorical & Decrease & Reference \\
\hline & & & No change & $\begin{array}{l}1.554(0.847-2.850) \\
p=0.155\end{array}$ \\
\hline & & & Increase & $\begin{array}{l}1.736(0.994-3.031) \\
p=0.052\end{array}$ \\
\hline & \multirow[t]{2}{*}{ Adjusted for smoking, deprivation } & & Decrease & Reference \\
\hline & & & No change & $\begin{array}{l}1.714(0.915-3.211) \\
p=0.092\end{array}$ \\
\hline
\end{tabular}


Table 3 Hazard ratios of first events for skirt size in 20s, skirt size at questionnaire completion, BMI and change in skirt size (95\% confidence intervals and $p$ values) (Continued)

\begin{tabular}{|c|c|c|c|}
\hline Variable & & & Hazard ratio $(95 \% \mathrm{Cl}$ \\
\hline & \multirow{4}{*}{$\begin{array}{l}\text { Adjusted for age, smoking, deprivation, hypertension, } \\
\text { heart disease, hypercholesterolaemia, stroke, diabetes, } \\
\text { rheumatoid arthritis, osteoarthritis, osteoporosis, alcohol } \\
\text { abstinence, alcohol } \geq 21 \text { units/week }\end{array}$} & Increase & $\begin{array}{l}1.873(1.050-3.343) \\
p=0.034\end{array}$ \\
\hline & & Decrease & Reference \\
\hline & & No change & $\begin{array}{l}1.781(0.950-3.337) \\
p=0.072\end{array}$ \\
\hline & & Increase & $\begin{array}{l}1.799(1.007-3.214) \\
p=0.047\end{array}$ \\
\hline
\end{tabular}

Similarly, a study nested in the fourth Glasgow monitoring cardiovascular (MONICA) disease risk factor survey measured height, weight, WC and hip circumference, and obtained SS in 161 women. Dress size correlated with WC and BMI. Dress size $\geq 18$ was associated with a significantly increased risk of cardiovascular disease [14].

\section{Conclusion}

We have demonstrated that SS in middle age is associated with increased risk of CLD. In post-menopausal women who develop liver disease, there is a significantly higher average SS when aged in their 20s (and in middle age). If these results are confirmed in further population studies, this may provide a simple way for women to stratify their risk of liver disease.

\section{Additional file}

Additional file 1: Table S1. ICD-10 codes and death certificate text of first LREs. Summary of the ICD-10 code(s) representing first presentation of liver-related event. Table S2. Hazard ratios for liver-related events for potential confounders (95\% confidence intervals and $p$ values). Univariate hazard ratios for liver-related events for smoking, deprivation, alcohol categories, alcohol $\geq 21$ units/week, abstinence from alcohol, BMI, hypertension, heart disease, hypercholesterolaemia, stroke, diabetes, rheumatoid arthritis, osteoarthritis, osteoporosis. (DOCX 95 kb)

\section{Abbreviations}

BMI: Body mass index; CLD: Chronic liver disease; HES: Hospital episode statistics; HR: Hazard ratio; ICD-10: International classification of disease 10th revision; IMD: Index of multiple deprivation; IQR: Interquartile range; LRE: Liverrelated event; NAFLD: Non-alcoholic fatty liver disease; NHS: National Health Service; SE: Standard error; SS: Skirt size; UKCTOCS: United Kingdom Collaborative Trial of Ovarian Cancer Screening; WC: Waist circumference

\section{Acknowledgements}

The authors are particularly grateful to the women throughout the UK who are participating in the trial and to the entire medical, nursing and administrative staff who worked on UKCTOCS.

\section{Funding}

UKCTOCS was core funded by the Medical Research Council, Cancer Research UK and National Institute of Health Research (NIHR), with additional support from the Special Trustees of Bart's and the London, the Special Trustees of University College London Hospitals (UCLH) and the Eve Appeal. Researchers at University College London are supported by the NIHR University College London Hospitals (UCLH) Biomedical Research Centre. WMR is a NIHR Senior Investigator. The funding source or the sponsor had no role in data collection, data analysis, data interpretation or writing of the report. The researchers are independent from the funders. No external funding for this nested study.

\section{Availability of data and materials}

The datasets used and/or analysed during the current study are available from the corresponding author on reasonable request.

\section{Authors' contributions}

All authors were involved in study design. PMT, SA, AGM, UM and WMR were involved in data collection. PMT, UM and WMR drafted the manuscripts and figs. PMT undertook the literature search. PMT, JP, ST, UM, WMR and MB performed the statistical analysis. All authors critically revised the manuscript and approved the final version.

\section{Ethics approval and consent to participate}

UKCTOCS was approved by the UK North West Multicentre Research Ethics Committee (North West MREC 00/8/34). All women provided written consent. The current study was approved by the National Research Ethics Service (NRES) Committee London - Bentham (Ref: 05/Q0505/57) on 10th August 2011.

\section{Consent for publication}

Not applicable.

\section{Competing interests}

UM has a financial interest through Abcodia Ltd in the third party exploitation of the UKCTOCS biobank. None of the other authors declared any conflicts of interest.

\section{Publisher's Note}

Springer Nature remains neutral with regard to jurisdictional claims in published maps and institutional affiliations.

\section{Author details}

${ }^{1}$ Institute for Liver and Digestive Health, Division of Medicine, University College London, Royal Free Hospital, Rowland Hill Street, NW3 2PF, London, UK. ${ }^{2}$ Gynaecological Cancer Research Centre, Department of Women's

Cancer, Institute for Women's Health, University College London, London, UK. ${ }^{3}$ Public Health Sciences and Medical Statistics, Faculty of Medicine, University of Southampton, Southampton, UK.

Received: 25 September 2017 Accepted: 13 March 2018

Published online: 27 March 2018

\section{References}

1. Leon DA, McCambridge J. Liver cirrhosis mortality rates in Britain from 1950 to 2002: an analysis of routine data. Lancet. 2006;367:52-6.

2. Williams R, Aspinall R, Bellis M, Camps-Walsh G, Cramp M, Dhawan A, et al. Addressing liver disease in the UK: a blueprint for attaining excellence in health care and reducing premature mortality from lifestyle issues of excess consumption of alcohol, obesity, and viral hepatitis. Lancet. 2014;384:1953-97.

3. Scaglione S, Kliethermes S, Cao G, Shoham D, Durazo R, Luke A, et al. The epidemiology of cirrhosis in the United States: a population-based study. J Clin Gastroenterol. 2015;49:690-6. 
4. Marchesini G, Brizi M, Bianchi G, Tomassetti S, Bugianesi E, Lenzi M, et al. Nonalcoholic fatty liver disease: a feature of the metabolic syndrome. Diabetes. 2001;50:1844-50.

5. Chang H, Simonsick EM, Ferrucci L, Cooper JA. Validation study of the body adiposity index as a predictor of percent body fat in older individuals: findings from the BLSA. J Gerontol A Biol Sci Med Sci. 2014;69:1069-75.

6. Lean ME, Han TS, Morrison CE. Waist circumference as a measure for indicating need for weight management. BMJ. 1995;311(6998):158-61.

7. Trembling PM, Apostolidou S, Gentry-Maharaj A, Parkes J, Ryan A, Tanwar S, et al. Risk of chronic liver disease in post-menopausal women due to body mass index, alcohol and their interaction: a prospective nested cohort study within the United Kingdom collaborative trial of ovarian Cancer screening (UKCTOCS). BMC Public Health. 2017:17(1):603.

8. Fourkala EO, Burnell M, Cox C, Ryan A, Salter LC, Gentry-Maharaj A, et al. Association of skirt size and postmenopausal breast cancer risk in older women: a cohort study within the UK collaborative trial of ovarian Cancer screening (UKCTOCS). BMJ Open. 2014;24(9):e005400.

9. Menon U, Gentry-Maharaj A, Hallett R, Ryan A, Burnell M, Sharma A, et al. Sensitivity and specificity of multimodal and ultrasound screening for ovarian cancer, and stage distribution of detected cancers: results of the prevalence screen of the UK collaborative trial of ovarian Cancer screening (UKCTOCS). Lancet Oncol. 2009;10:327-40.

10. Menon U, Gentry-Maharaj A, Ryan A, Sharma A, Burnell M, Hallett R, et al. Recruitment to multicentre trials-lessons from UKCTOCS: descriptive study. BMJ. 2008;337:a2079.

11. Gentry-Maharaj A, Glazer C, Burnell M, Ryan A, Berry H, Kalsi J, et al. Changing trends in reproductive/lifestyle factors in UK women: descriptive study within the UK collaborative trial of ovarian Cancer screening (UKCTOCS). BMJ Open. 2017;7:e011822.

12. Menon U, Ryan A, Kalsi J, Gentry-Maharaj A, Dawnay A, Habib M, et al. Risk algorithm using serial biomarker measurements doubles the number of screen-detected cancers compared with a single-threshold rule in the United Kingdom collaborative trial of ovarian Cancer screening. J Clin Oncol. 2015;33:2062-71.

13. Jacobs IJ, Menon U, Ryan A, Gentry-Maharaj A, Burnell M, Kalsi JK. Ovarian cancer screening and mortality in the UK collaborative trial of ovarian Cancer screening (UKCTOCS): a randomised controlled trial. Lancet. 2016; 387(10022):945-56.

14. Han TS, Gates E, Truscott E, Lean ME. Clothing size as an indicator of adiposity, ischaemic heart disease and cardiovascular risks. J Hum Nutr Diet. 2005:18:423-30.

15. British Standards Institution. BS 3666:1982 Specification for size designation of women's wear. London.

16. Drinkaware. Alcohol unit guidelines. Drinkaware, London. www.drinkaware.co.uk Accessed 21 Feb 2017.

17. Burnell M, Gentry-Maharaj A, Ryan A, Apostolidou S, Habib M, Kalsi J, et al. Impact on mortality and cancer incidence rates of using random invitation from population registers for recruitment to trials. Trials. 2011;12:61.

18. Liu B, Balkwill A, Reeves G, Beral V. Body mass index and risk of liver cirrhosis in middle aged UK women: prospective study. BMJ. 2010;340:c912.

19. Donato GB, Fuchs SC, Oppermann K, Bastos C, Spritzer PM. Association between menopause status and central adiposity measured at different cutoffs of waist circumference and waist-to-hip ratio. Menopause. 2006;13:280-5.

20. Garcia-Tsao G, Friedman S, Iredale J, Pinzani M. Now there are many (stages) where before there was one: in search of a pathophysiological classification of cirrhosis. Hepatology. 2010;51:1445-9.

21. Diehl AM. Obesity and alcoholic liver disease. Alcohol. 2004;34:81-7.

22. Health and Social Care Information Centre. Health Survey for England 2015: Adult alcohol consumption. HSIC, 2016.

23. Department of Health. Adult alcohol statistics from the National Drug Treatment Monitoring System (NDTMS) 1 April 2013 to 31 march 2014. London: Department of Health; 2014.

24. Bolton-Smith C, Woodward M, Tunstall-Pedoe H, Morrison C. Accuracy of the estimated prevalence of obesity from self reported height and weight in an adult Scottish population. J Epidemiol Community Health. 2000;54:143-8.

25. Hill A, Roberts J. Body mass index: a comparison between self-reported and measured height and weight. J Public Health Med. 1998;20(2):206-10.

26. Nieto-Garcia FJ, Bush TL, Keyl PM. Body mass definitions of obesity: sensitivity and specificity using self-reported weight and height. Epidemiology. 1990;1:146-52.
27. Roberts RJ. Can self-reported data accurately describe the prevalence of overweight? Public Health. 1995;109(4):275-84.

28. Kuskowska-Wolk A, Karlsson P, Stolt M, Rössner S. The predictive validity of body mass index based on self-reported weight and height. Int J Obes. 1989;13:441-53.

29. Dahl AK, Hassing LB, Fransson El, Pedersen NL. Agreement between selfreported and measured height, weight and body mass index in old age-a longitudinal study with 20 years of follow-up. Age Ageing. 2010;39:445-51.

30. Stevens J, Keil JE, Waid LR, Gazes PC. Accuracy of current, 4-year, and 28year self-reported body weight in an elderly population. Am J Epidemiol. 1990:132:1156-63.

31. Dahl AK, Reynolds CA. Accuracy of recalled body weight-a study with 20years of follow-up. Obesity (Silver Spring). 2013;21:1293-8.

32. Perry GS, Byers TE, Mokdad AH, Serdula MK, Williamson DF. The validity of self-reports of past body weights by U.S. adults. Epidemiology. 1995;6:61-6.

33. Must A, Willett WC, Dietz WH. Remote recall of childhood height, weight, and body build by elderly subjects. Am J Epidemiol. 1993;138:56-64.

34. Office for National Statistics. Live births in England and Wales by characteristics of mother 1, 2010. ONS, London. www.ons.gov.uk/ons/rel/ vsob1/characteristics-of-Mother-1\%2D-england-and-wales/2010/index.html. Accessed 31 Jan 2018

35. Aydinoğlu NZ, Krishna A. Imagining thin: why vanity sizing works. J Consum Psychol. 2012;22:565-72.

36. Howard SJ, Davies SC. Chief medical officer urges action to tackle overweight and obesity. BMJ. 2014;348:92375.

37. Li L, Liu DW, Yan HY, Wang ZY, Zhao SH, Wang B. Obesity is an independent risk factor for non-alcoholic fatty liver disease: evidence from a meta-analysis of 21 cohort studies. Obes Rev. 2016;17:510-9.

38. Xu C, Yu C, Ma H, Xu L, Miao M, Li Y. Prevalence and risk factors for the development of nonalcoholic fatty liver disease in a nonobese Chinese population: the Zhejiang Zhenhai study. Am J Gastroenterol. 2013;108:1299-304.

39. Loomis AK, Kabadi S, Preiss D, Hyde C, Bonato V, St Louis M, et al. Body mass index and risk of nonalcoholic fatty liver disease: two electronic health record prospective studies. J Clin Endocrinol Metab. 2016;101:945-52.

40. Hughes LA, Schouten LJ, Goldbohm RA, van den Brandt PA, Weijenberg MP. Self-reported clothing size as a proxy measure for body size. Epidemiology. 2009;20:673-6.

41. Battram DS, Beynon C, He M. The reliability and validity of using clothing size as a proxy for waist circumference measurement in adults. Appl Physiol Nutr Metab. 2011;36:183-90.

\section{Submit your next manuscript to BioMed Central and we will help you at every step:}

- We accept pre-submission inquiries

- Our selector tool helps you to find the most relevant journal

- We provide round the clock customer support

- Convenient online submission

- Thorough peer review

- Inclusion in PubMed and all major indexing services

- Maximum visibility for your research

Submit your manuscript at www.biomedcentral.com/submit 